\title{
BIOSYNTHESIS AND CHARACTERIZATION OF SILVER NANOPARTICLES USING FIG (FICUS CARICA) LEAVES: A POTENTIAL ANTIMICROBIAL ACTIVITY
}

\author{
ACAY, $\mathrm{H}$. \\ Department of Nutrition and Dietetic, School of Health, Mardin Artuklu University \\ Mardin, Turkey \\ (e-mail: hilalacay@gmail.com)
}

(Received $10^{\text {th }}$ May 2019; accepted $16^{\text {th }} \mathrm{Jul} 2019$ )

\begin{abstract}
Environmentally friendly methods for obtaining nanomaterials see a great interest. In addition to being inexpensive, the easy implementation process and the advantages of synthesis without toxic chemicals are the main reasons of interest. In this study, silver nanoparticles (AgNPs) were successfully synthesized using fig (Ficus carica) leaf extract. The formation and the presence of AgNPs were observed using ultraviolet-visible spectrophotometry (UV-Vis). Peaks with a maximum wavelength of $419 \mathrm{~nm}$ are identified in the measurements. Phytochemicals in the extract responsible for functional groups providing reduction and stability were evaluated using Fourier transform infrared spectroscopy (FT-IR) data. The Scanning electron microscopy-Energy Dispersive X-Ray Spectrum (SEM-EDX) analysis showed that the AgNPs were spherical and the elemental composition contained mostly silver. X-ray diffractometer (XRD) results revealed that the peaks $111^{\circ}, 200^{\circ}, 220^{\circ}$ and $311^{\circ}$ belong to the characteristic structure of silver and have a crystal dimension of $17.30 \mathrm{Nm}$ using Debye-Scherrer equation. In thermogravimetric - differential thermal analysis (TGA-DTA) analysis, the degradation temperatures of AgNPs were evaluated. AgNPs showed antimicrobial activity on various microorganisms even at very high concentrations. As a solution to the antimicrobial search, it can be developed in medical industry.
\end{abstract}

Keywords: XRD, SEM, TGA-DTA, AgNPs, Ficus carica

\section{Introduction}

Nanomaterials are used in medical, electronic, food and cosmetic industries, textile industry, agricultural applications and many other areas (Alqahtani et al., 2017; El-Batal et al., 2018; Silva-Ichante et al., 2018; Rolim et al., 2019). Among nanomaterials, AgNPs have a large facial area, good thermal and electrical conductivity (Elemike et al., 2016). AgNP are obtained using different methods (Fig. 1) (Mittal et al., 2013). Since physical and chemical methods are being synthesized by using high amounts of energy and toxic chemicals, they are a disadvantage compared to biological methods. Biological source synthesis methods are cheaper and the process is simpler and easier. It also makes these methods more advantageous because they do not contain toxic chemicals during the synthesis phase (Pantidos and Horsfall, 2014; Tippayawat et al., 2016; Kanchi et al., 2018). Phytochemicals such as polyphenols, flavonoids, proteins, alcohols and sugars found in plants, rather than harmful chemicals, are responsible for both reduction and stability (Kumar et al., 2015). Phytochemicals are responsible for the synthesis of AgNPs by reducing the Ag+ form to AgO (Prakash et al., 2013). Obtaining nanoparticles from plant sources provides advantages such as easy processing and no culture (Pallela et al., 2018). Furthermore, AgNPs have been shown to exhibit antimicrobial activity in some studies (Veerasamy et al., 2011; Ghosh et al., 2012; Ashajyothi et al., 2016). 


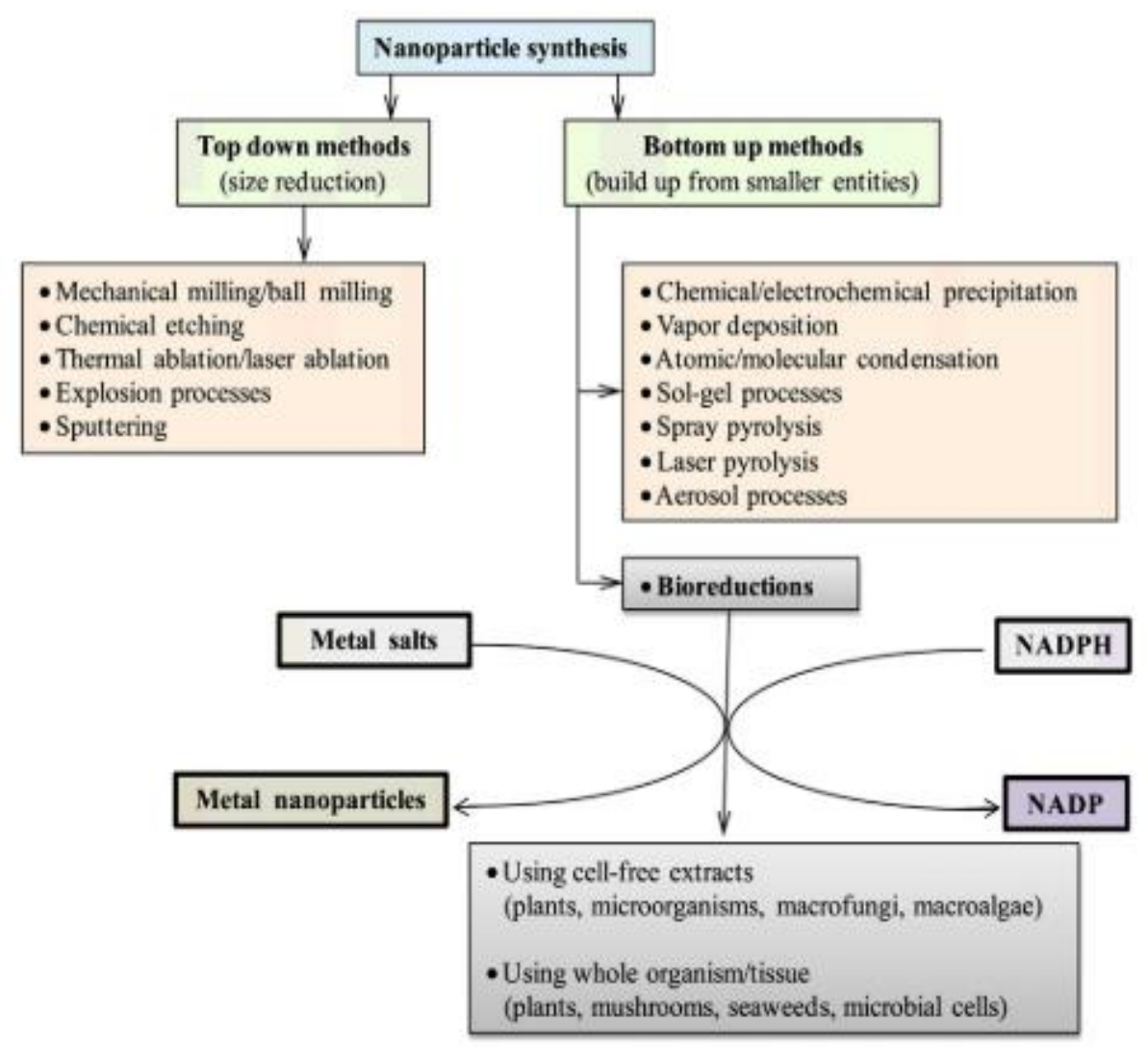

Figure 1. Nanoparticle forming methods (Mittal et al., 2013)

The aim of this study is to synthesize AgNPs with fig (Ficus carica) leaf extract in an inexpensive and simple way and to investigate the anti-microbial effects of these NPs characterized by different analysis data.

\section{Materials and methods}

\section{Plant leaf}

Fig (Ficus carica) leaf used in the study was obtained from Mardin, Sultan Village/Turkey in May-June 2018. $500 \mathrm{~g}$ samples stored in the MicrobiologyBiochemistry Research Laboratory of Mardin Artuklu University

\section{Microorganisms}

For testing antimicrobial activity; Escherichia coli ATCC 25922, Staphylococcus aureus ATCC 25923, Streptococcus pyogenes ATCC 19615 Pseudomonas aeruginosa ATCC 27853, standard bacterial strains with Candida albicans ATCC 10231 strains are available in the Microbiology-Biochemistry Research Laboratory of Mardin Artuklu University. 


\section{Preparation of fig (Ficus carica) leaf extract and silver nitrate $\left(\mathrm{AgNO}_{3}\right)$ solution}

The green leaves of fig fruit were collected in the center of Mardin, Sultan Village/Turkey. After washing with tap water, washing was done several times with distilled water. Dried leaves were minimized prior to preparation of the extract. $100 \mathrm{~g}$ was taken and mixed with $500 \mathrm{ml}$ distilled water and left to boil. After boiling, the room was cooled and filtered several times by using the rough filter paper first and then the Whattman No.1 filter paper. After being filtered for several times, it was kept at $+4{ }^{\circ} \mathrm{C}$ for synthesis. $1 \mathrm{mM}$ aqueous solution was prepared with silver nitrate (AgNO3) of 99.8\% purity was purchased from Alfa Aesar.

\section{Synthesis and characterization}

$500 \mathrm{ml}$ extract and $2000 \mathrm{ml} \mathrm{AgNO}_{3}$ solution were mixed and kept constant in room conditions. The color change was observed for $50 \mathrm{~min}$ depending on the time. The presence of AgNPs was checked by examining absorbance values for the color change using Perkin Elmer one UV Visible Spectrophotometer. The characterization of silver nanoparticles was carried out as follows according to the methods described earlier (Baran, 2018). FTIR analysis was performed to evaluate phytochemicals responsible for reduction by using Perkin Elmer Spectrum One. The post-synthesized content in liquid form was centrifuged with OHAUS FC 5706 model device at 6,000 rpm for $25 \mathrm{~min}$ and the particles used for further characterization steps were precipitated. The particles were dried at $65{ }^{\circ} \mathrm{C}$. RadB-DMAX II computer-controlled Energy Dispersive X-Ray diffractometer (EDX) was used to evaluate the elemental composition of the particles. Morphological images were examined with scanning electron microscope EVO 40 LEQ (SEM) data. The crystal structure of the particles was evaluated by RadB-DMAX II computer-controlled X-ray diffractometer (XRD) analysis. Crystalline particle size was determined by using the debye-Scherrer equation, using the Shimadzu TGA-50 device to control the decomposition temperature of the particles with TGA-DTA.

\section{Determination of antimicrobial effects of silver nanoparticles}

The antimicrobial effects of the particles on gram negative Escherichia coli ATCC 25922, P. aeruginosa ATCC 27853, gram positive Staphylococcus aureus ATCC 29213, $S$. pyogenes ATTC 19615 bacteria and Candida albicans yeast were determined by using micro dilution method to determine the minimum inhibition concentration (MIC). In practice, the muller Hilton medium was added to the microplate wells and incubated overnight at $37^{\circ} \mathrm{C}$ by addition of an appropriate amount of the microorganism mixture and the AgNP solution adjusted to 0.5 in turbidity according to the Mc Farland standard. The lowest concentration in the absence of reproduction after incubation was determined as the MIC value (El-Batal et al., 2018; Vishwasrao et al., 2018). Commercial antibiotics were used as control for Gram (+) (vancomycin), Gram (-) (colistin) bacteria and fungus (fluconazole). In addition, the effect of $\mathrm{AgNO}^{3}$ solution was investigated. The study was performed with 3 repetitions and the mean values were determined as MIC value.

\section{Results and discussion}

After mixing $1 \mathrm{mM} \mathrm{AgNO}_{3}$ solution with leaf extract, the color rapidly changed from light to dark brown was observed after $30 \mathrm{~min}$. Maximum absorbance data at $419 \mathrm{~nm}$ is given in Figure 2. 

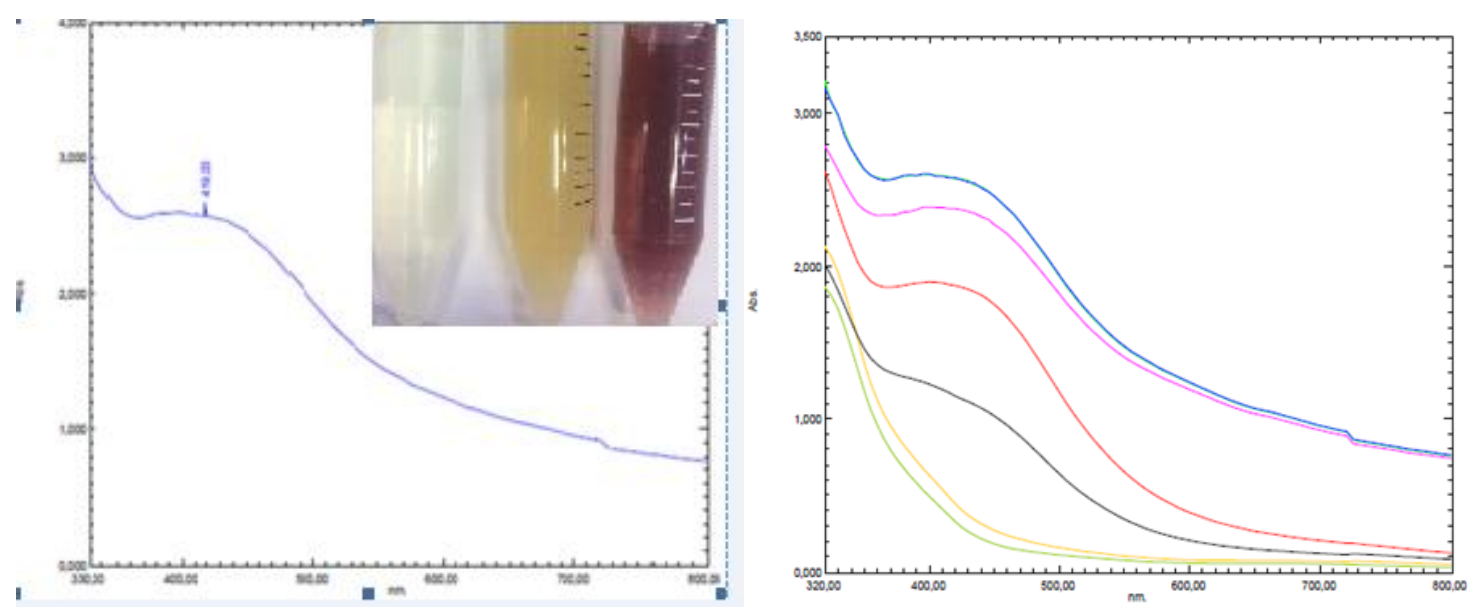

Figure 2. UV-Vis. analysis result data

Functional groups involved in the reduction of AgNPs were investigated by FTIR analysis (Fig. 3).

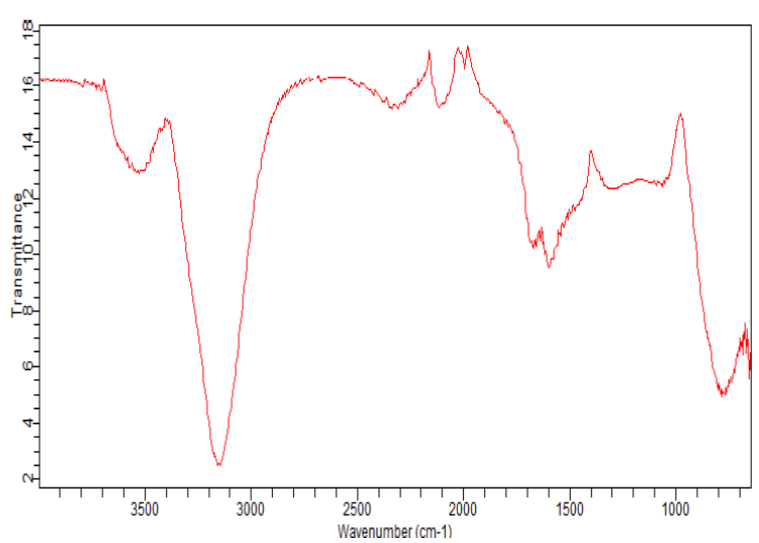

A

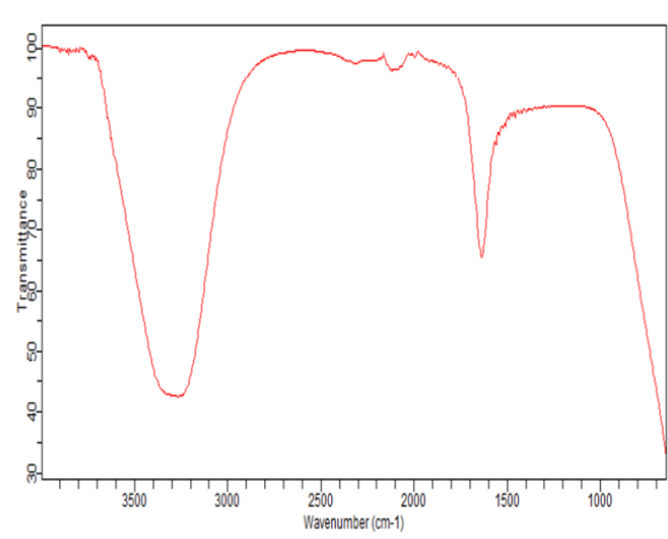

B

Figure 3. With FTIR analysis result data. A Extract, B evaluation of functional groups after synthesis

In the XRD results, the peaks $111^{\circ}, 200^{\circ}, 220^{\circ}$ and $311^{\circ}$ are the peaks that correspond to $2 \theta$, which represent the cubic crystal structure of silver (Fig. 4). The numerical values corresponding to these peaks were found to be 38.10, 44.24, 64.54 and 77.50. The crystal size of AgNPs were calculated $17.30 \mathrm{~nm}$ by using the DebyeScherrer formula (Eq. 1) (Baran, 2019).

$$
D=K \lambda /(\beta \cos \theta)
$$

In Equation 1: $\mathrm{D}=$ particle size $(\mathrm{nm}), \mathrm{K}=$ fixed $(0.90), \lambda=$ wavelength $\mathrm{X}$-ray $\left(1.5406^{\circ} \mathrm{A}\right), \beta=$ half of the highest peak value is specified in radians (FWHM), $\theta=$ fracture angle.

When the SEM analysis data were examined, it was found that AgNPs were in spherical appearance (Fig. 5). 


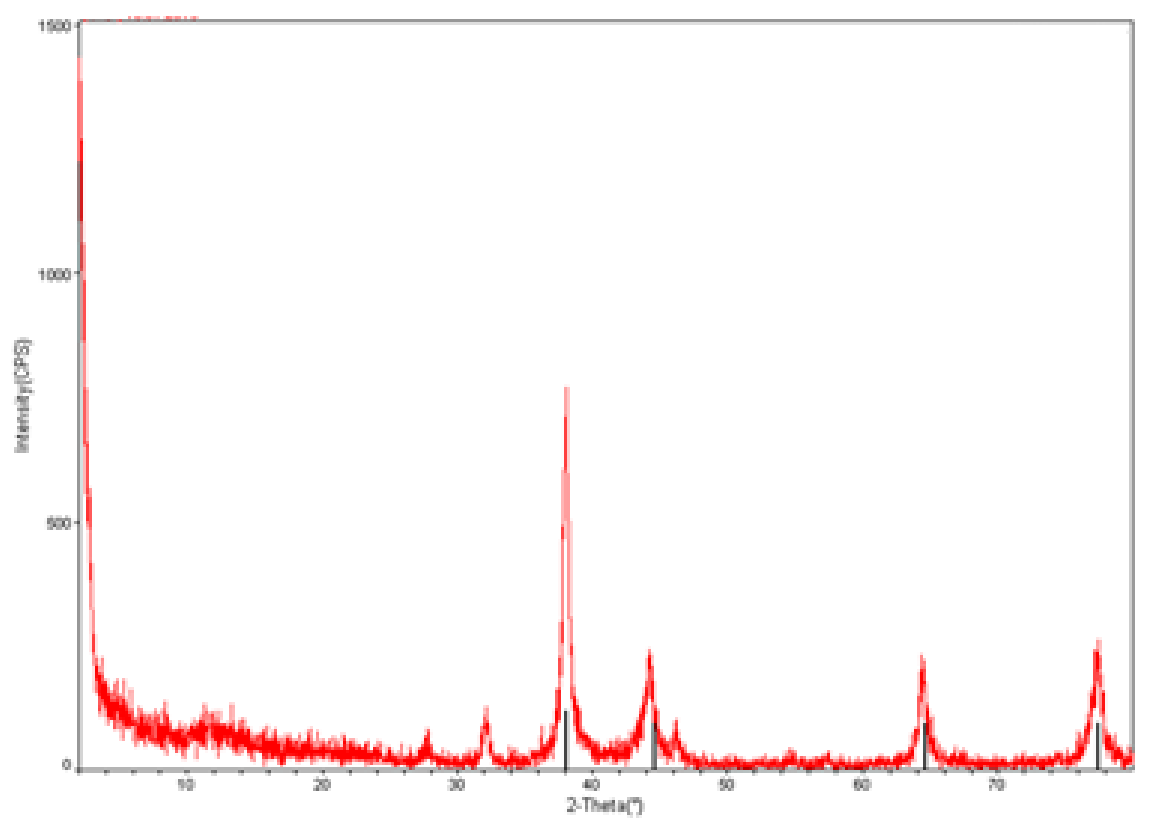

Figure 4. Investigation of crystal structure and silver phases of AgNPs by XRD analysis

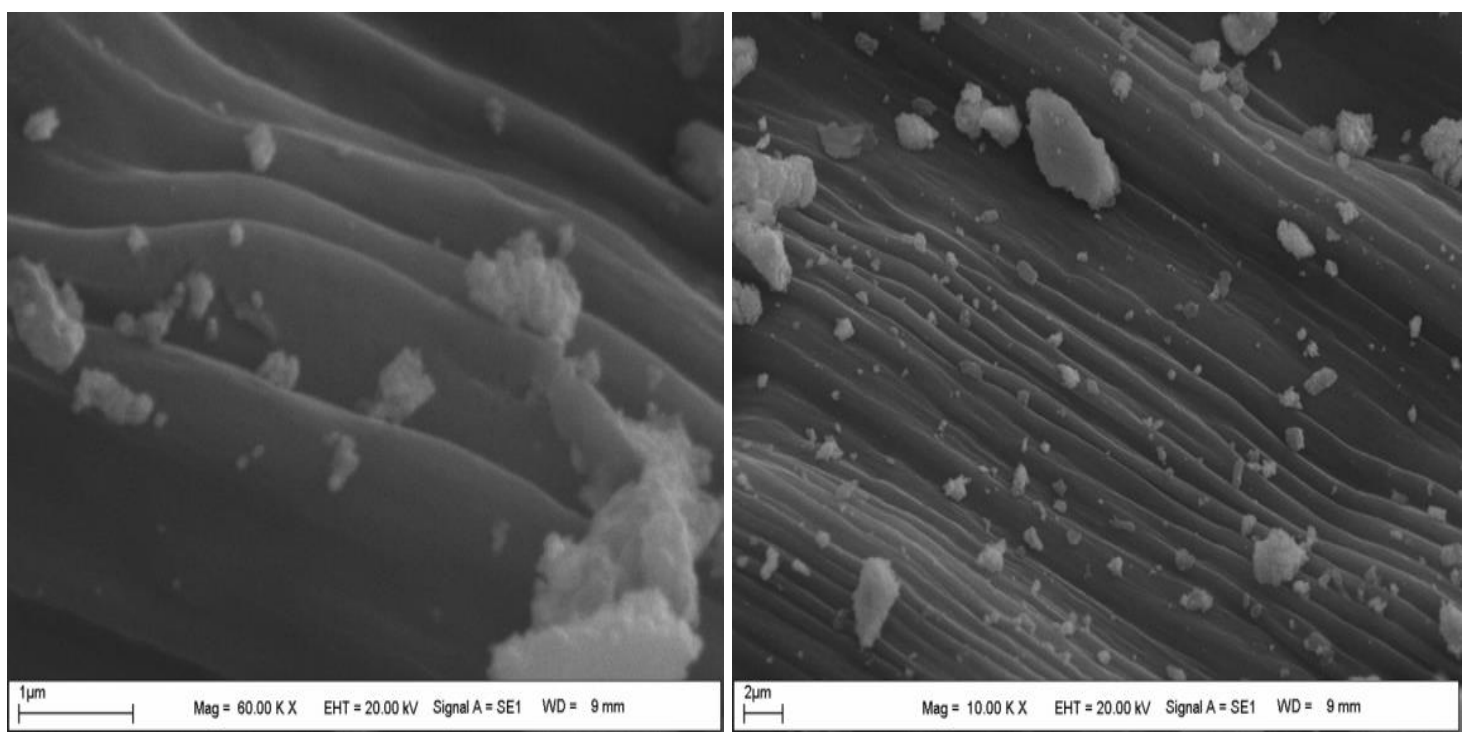

Figure 5. Evaluation of morphology of AgNPs in SEM results

The results of EDX showed a large percentage of the element content (Fig. 6). The TGA-DTA findings of the synthesized AgNPs were analyzed at a flow rate of $20 \mathrm{~mL} / \mathrm{min}$ in the $\mathrm{N}_{2}(\mathrm{~g})$ atmosphere with a heating rate of $10^{\circ} \mathrm{C} / \mathrm{min}$ between 12 and $1000{ }^{\circ} \mathrm{C}$ (Fig. 7) (Eren and Baran, 2019).

In the study, AgNPs were found to be effective at lower concentrations than antibiotic and $5 \mathrm{mM}$ silver nitrate solution. The MIC values of $S$. aureus, S. pyogenes $E$. coli $P$. aeruginosa and $C$. albicans respectively $0.225,0.056,0.112,0.112$ and $0.450 \mathrm{mg} \mathrm{L}^{-1}$ results were obtained (Table 1). Compared with silver nitrates and antibiotics, AgNPs synthesized using plant extract can be used as an alternative to existing antibiotics as a result. 


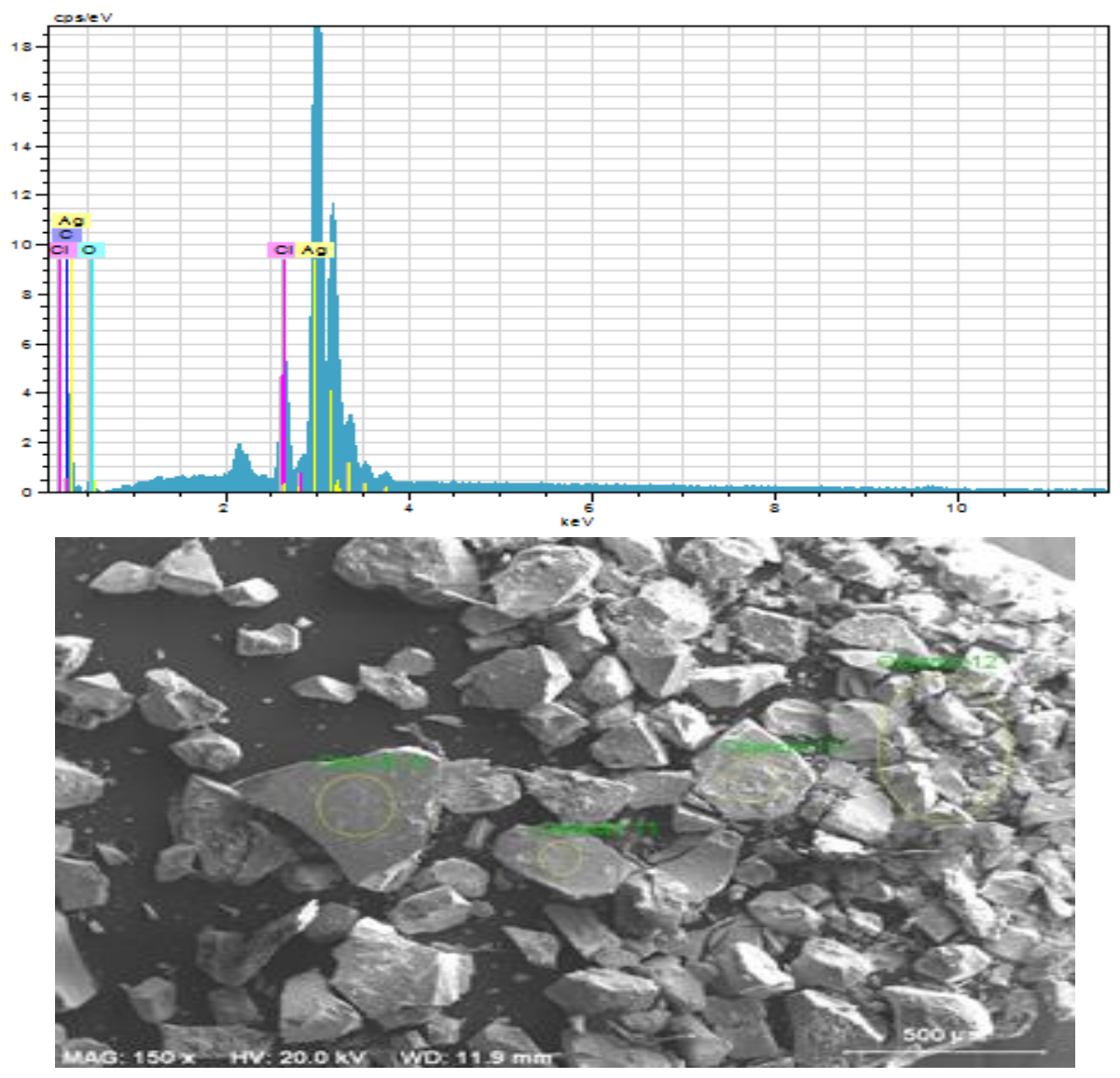

Figure 6. Analysis of the elemental composition by the EDX analysis of AgNPs
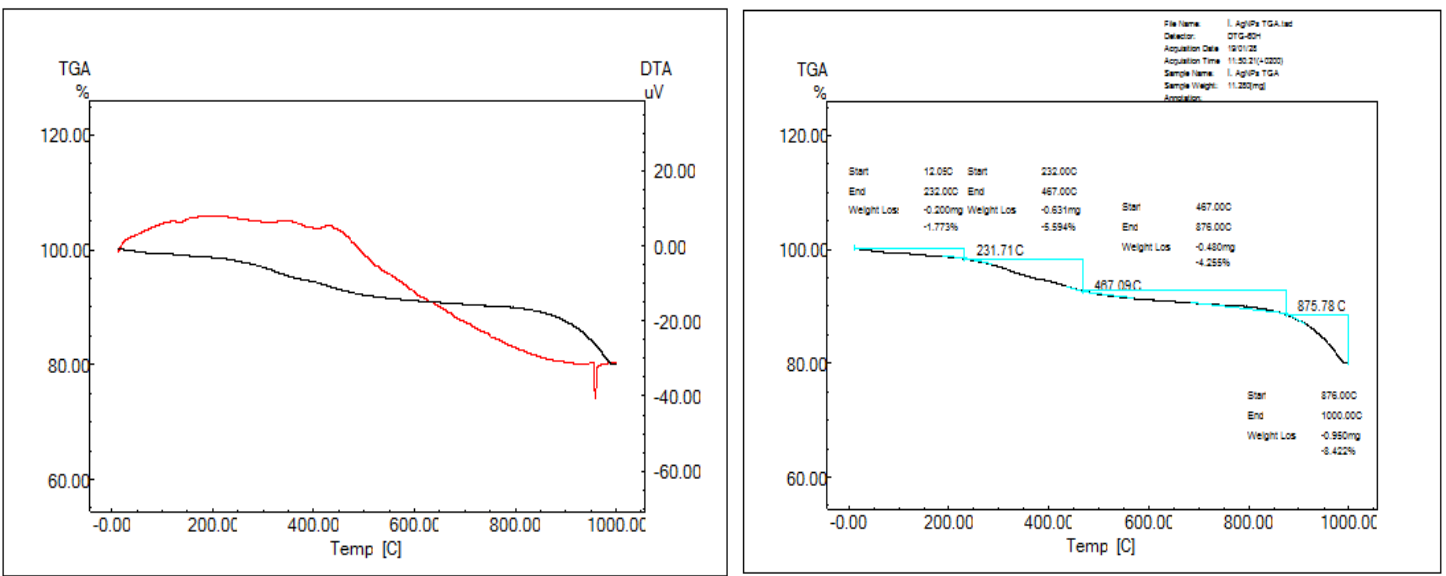

Figure 7. TGA-DTA data of the synthesized nanoparticle

In the synthesis of AgNPs using the fig leaf extract, the dark brown color change vibrations on the plasma surface and the UV-Vis. The data on the maximum absorbance of $419 \mathrm{~nm}$ in spectrophotometer measurements gives us characteristic data showing the formation and presence of AgNPs (Link and Wang, 1999; Hemmati et al., 2019). In similar synthesis studies of plant origin there are values of absorbance supporting this data (Shahverdi et al., 2007; Kumar et al., 2017; Selvakumar et al., 2018). The peak at 
$3529 \mathrm{~cm}^{-1}$ is $-\mathrm{NH}$ stretching, the peak at $1599 \mathrm{~cm}^{-1}$ may belong to $-\mathrm{C}=\mathrm{O}$ or I amide band, and the peak in $\mathrm{cm}^{-1} 3180$ is considered to be phenol or alcohol-induced-OH. During the formation of nanoparticles, role of $-\mathrm{OH},-\mathrm{NN}$ and $\mathrm{C}=\mathrm{O}$ groups shift in the reduction is shown. In the synthesis studies to obtained AgNPs, almost identical functional groups were said to be responsible for reduction (Baran, 2019). In the XRD results, the peaks $111^{\circ}, 200^{\circ}, 220^{\circ}$ and $311^{\circ}$ are the peaks that correspond to $2 \theta$, which represent the cubic crystal structure of silver. Some studies have characterized these data with AgNPs (Narayanan and Sakthivel, 2010; Hemmati et al., 2019). The crystal size of AgNPs was calculated $17.30 \mathrm{~nm}$ by using the Debye-Scherrer formula. After the synthesis of nanoparticles, there are studies that calculate crystal size using this equation (Senapati et al., 2014; Palanisamy et al., 2017). The SEM results indicate that AgNPs have spherical morphology. In other studies, it has been reported that AgNPs have a spherical appearance (Pugazhendhi et al., 2018; Vishwasrao et al., 2018; Rolim et al., 2019).

Table 1. MIC values of Synthesized silver nanoparticles $(A g N P)\left(m g ~ m L^{-1}\right)$ on Silver nitrate solution and vancomycin, fluconazole, colistin antibiotics, S. Aureus, S. pyogenes, S. albicans and E. Coli, P. aeruginosa microorganisms

\begin{tabular}{c|c|c|c|c}
\hline & Organism & AgNPs & Silver nitrat & Antibiotic \\
\hline \multirow{4}{*}{ Gram positive } & $\begin{array}{c}\text { S. aureus } \\
\text { ATCC 29213 }\end{array}$ & 0.225 & 2.65 & 1 \\
\cline { 2 - 5 } & $\begin{array}{c}\text { S. pyogenes } \\
\text { ATTC 19615 }\end{array}$ & 0.056 & 1.32 & 1 \\
\hline \multirow{3}{*}{ Gram negative } & $\begin{array}{c}\text { E. coli } \\
\text { ATCC25922 }\end{array}$ & 0.112 & 0.66 & 2 \\
\cline { 2 - 5 } & $\begin{array}{c}\text { P. aeruginosa } \\
\text { ATCC 27853 }\end{array}$ & 0.112 & 0.66 & 2 \\
\hline \multirow{2}{*}{ Fungi } & C. albicans & 0.450 & 0.66 & 2 \\
\hline
\end{tabular}

In the EDX analysis, it was observed that the content of the element belonged largely to silver. In similar studies, the element composition was evaluated (Owaid et al., 2015; Khan et al., 2018; Acay et al., 2019). In TGA-DTA data, it is understood that the mass loss of the nanoparticles at $12-232^{\circ} \mathrm{C}$ is due to moisture and the mass loss at 232 $467{ }^{\circ} \mathrm{C}$ is due to the structure of the extract and that the material is now gradually degraded at $467-876{ }^{\circ} \mathrm{C}$ in Figure 5 (Baran et al., 2018; Baran, 2019). We have investigated the effective antimicrobial activity of AgNPs. This activity was effective even at lower concentrations than commercial antibiotic and $5 \mathrm{mM}$ silver nitrate solution. Studies have shown that AgNPs have a negative effect on the reproduction of microorganisms and that they have put pressure on them (Pugazhendhi et al., 2018). These NPs produce ROS (Reactive Oxygen Species), suppressing the membrane structure, proteins, DNA and other vital functions of microorganisms and suppressing their function (Acay et al., 2019). Environmentally friendly synthesis methods for the production of nanomaterials are in the focus of interest due to their lack of toxic chemicals, economical and easier synthesis process. At the same time, the fields of use are becoming widespread every day. 


\section{Conclusions}

The advantages of nanoparticles synthesized by biological methods are hygienic working environment, health and environmental protection, less waste and providing the most stable products. Green-synthesized Ag-NPs can be evaluated in a variety of applications including cardiovascular implants, dentistry, medicine, therapeutics, biosensors, agriculture and more, both now and in the future. In this context, It was synthesized AgNPs from the leaves of the Ficus carica plant with an easy, inexpensive, environmentally friendly method and without creating any special conditions (temperature, rinse, light, etc.). It was revealed that these particles are in a spherical view with a maximum absorption of $419 \mathrm{~nm}$ and that the crystal particle size is $17.30 \mathrm{~nm}$. The degradation temperatures of these AgNPs were found to be $876{ }^{\circ} \mathrm{C}$, and this is an indication of the durability of the product. It was found that these particles showed strong anti-microbial activity. NPs increasingly used for medical applications are of great interest as an approach to killing or reducing the activity of a large number of microorganisms. As a result, the AgNPs obtained is an alternative that can be developed and used in biotechnological and medical applications

\section{REFERENCES}

[1] Acay, H., Baran, M. F., Eren, A. (2019): Investigating antimicrobial activity of silver nanoparticles produced through green synthesis using leaf extract of common grape (Vitis vinifera). - Applied Ecology and Environmental Research 17(2): 4539-4546.

[2] Alqahtani, F. S., Alshebly, M. M., Govindarajan, M., Senthilmurugan, S., Vijayan, P., Benelli, G. (2017): Green and facile biosynthesis of silver nanocomposites using the aqueous extract of Rubus ellipticus leaves: toxicity and oviposition deterrent activity against Zika virus, malaria and filariasis mosquito vectors. - J Asia Pac Entomol 20(1): 157-164.

[3] Ashajyothi, C., Prabhurajeshwar, C., Handral, H. K., Kelmani, C. R. (2016): Investigation of antifungal and anti-mycelium activities using biogenic nanoparticles: an eco-friendly approach. - Environ Nanotechnology Monit Manag 5: 81-87.

[4] Baran, M. F. (2018): Green synthesis of silver nanoparticles (AgNPs) using Pistacia terebinthus leaf extract: antimicrobial effect and characterization EJONS. - International Journal on Mathematic, Engineering and Natural Sciences (5)67-75.

[5] Baran, M. F. (2019): Synthesis, characterization and investigation of antimicrobial activity of silver nanoparticles from Cydonia oblonga leaf. - Applied Ecology and Environmental Research 17(2): 2583-2592.

[6] Baran, M. F., Koç, A., Uzan, S. (2018): Synthesis, characterization and antimicrobial applications of silver nanoparticles (AgNPs) with kenger (Gundelia tournefortii) leaf. EJONS International J on Math, Eng and Natural Sci 5(2): 44-52.

[7] El-Batal, A. I., Al-Hazmi, N. E., Mosallam, F. M., El-Sayyad, G. S. (2018): Biogenic synthesis of copper nanoparticles by natural polysaccharides and Pleurotus ostreatus fermented fenugreek using gamma rays with antioxidant and antimicrobial potential towards some wound pathogens, Microb Pathog 118(March): 159-169.

[8] Elemike, E. E., Onwudiwe, D. C., Mkhize, Z. (2016): Eco-friendly synthesis of AgNPs using Verbascum thapsus extract and its photocatalytic activity. - Mater Lett 185: 452455 .

[9] Eren, A., Baran, M. F. (2019): Green synthesis, characterization and antimicrobial activity of silver nanoparticles (AgNPs) from maize (Zea mays). - Applied Ecology and Environmental Research 17(2): 4097-4105. 
[10] Ghosh, S., Patil, Ahire, Kitture, R., Kale, S., Pardesi, Cameotra, Bellare, J., Dhavale, Jabgunde, Chopade, B. (2012): Synthesis of silver nanoparticles using Dioscorea bulbifera tuber extract and evaluation of its synergistic potential in combination with antimicrobial agents. - Int J Nanomedicine 7: 483-496.

[11] Hemmati, S., Rashtiani, A., Zangeneh, M. M., Mohammadi, P., Zangeneh, A., Veisi, H. (2019): Green synthesis and characterization of silver nanoparticles using Fritillaria flower extract and their antibacterial activity against some human pathogens. Polyhedron 158(May): 8-14.

[12] Kanchi, S., Kumar G., Lo, A. Y., Tseng, C. M., Chen, S. K., Lin, C. Y. et al. (2018): Exploitation of de-oiled jatropha waste for gold nanoparticles synthesis: a green approach. - Arab J Chem 11(2) 247-255.

[13] Khan, A. U., Yuan, Q., Zia Ul Haqkhan, Ahmad, A., Khan, F. U., Tahir, K., Shakeel, M., Ullah, S. (2018): An eco-benign synthesis of AgNPs using aqueous extract of Longan fruit peel: antiproliferative response against human breast cancer cell line MCF-7, antioxidant and photocatalytic deprivation of methylene blue. - J Photochem Photobiol B Biol. 183: 367-373.

[14] Kumar, B., Smita, K., Cumbal, L., Debut, A. (2015): Green synthesis of silver nanoparticles using Andean blackberry fruit extract. - Saudi J Biol Sci 24(1) 45-50.

[15] Kumar, V., Singh, D. K., Mohan, S., Gundampati, R. K., Hasan, S. H. (2017): Photoinduced green synthesis of silver nanoparticles using aqueous extract of Physalis angulata and its antibacterial and antioxidant activity. - J Environ Chem Eng 5(1) 744756.

[16] Link, S., Wang, Z. L. (1999): Alloy formation of gold - silver nanoparticles and the dependence of the plasmon absorption on their composition. - J. Phys. Chem. B 103(18): 3529-3533.

[17] Mittal, A. K., Chisti, Y., Banerjee, U. C. (2013): Synthesis of metallic nanoparticles using plant extracts. - Biotechno Adv 31(2): 346-356.

[18] Narayanan, K. B., Sakthivel, N. (2010): Phytosynthesis of gold nanoparticles using leaf extract of Coleus amboinicus Lour. - Mater Charact 61(11): 232-1238.

[19] Owaid, M. N., Raman, J., Lakshmanan, H., Al-Saeedi, S. S. S., Sabaratnam, V., Ali Abed, I. (2015): Mycosynthesis of silver nanoparticles by Pleurotus cornucopiae var. citrinopileatus and its inhibitory effects against Candida sp. - Mater Lett 153: 186-190.

[20] Palanisamy, S., Rajasekar, P., Vijayaprasath, G., Ravi, G., Manikandan, R., Marimuthu, P. N. (2017): A green route to synthesis silver nanoparticles using Sargassum polycystum and its antioxidant and cytotoxic effects: an in vitro analysis. - Mater Lett 189: 196-200.

[21] Pallela, P. N. V. K., Ummey, S., Ruddaraju, L., Pammi, S. V. N., Yoon, S. G. (2018): Ultra Small, mono dispersed green synthesized silver nanoparticles using aqueous extract of Sida cordifolia plant and investigation of antibacterial activity. - Microb Pathog 124: 63-69.

[22] Pantidos, N., Horsfall, L. E. (2014): Biological synthesis of metallic nanoparticles by bacteria, fungi and plant. - J Nanomed Nanotechnol 5(5): 10.

[23] Prakash, P., Gnanaprakasam, P., Emmanuel, R., Arokiyaraj, S., Saravanan, M. (2013): Green synthesis of silver nanoparticles from leaf extract of Mimusops elengi, Linn. for enhanced antibacterial activity against multi drug resistant clinical isolates. - Colloids Surfaces B Biointerfaces 108: 255-259.

[24] Pugazhendhi, S., Palanisamy, P. K., Jayavel, R. (2018): Synthesis of highly stable silver nanoparticles through a novel green method using Mirabillis jalapa for antibacterial, nonlinear optical applications. - Opt Mater (Amst) 79: 457-463.

[25] Rolim, W. R., Pelegrino, M. T., De Araújo, L. B., Ferraz, L. S., Costa, F. N., Bernardes, J. S., Rodigues, T., Brocchi, M., Seabra, A. B. (2019): Green tea extract mediated biogenic synthesis of silver nanoparticles: Characterization, cytotoxicity evaluation and antibacterial activity. - Appl Surf Sci 463(August): 66-74. 
[26] Selvakumar, P., Sithara, R., Viveka, K., Sivashanmugam, P. (2018): Green synthesis of silver nanoparticles using leaf extract of Acalypha hispida and its application in blood compatibility. - J Photochem Photobiol B Biol 182(December): 52-61.

[27] Senapati, S., Syed, A., Khan, S., Pasricha, R., Khan, M. I., Kumar, R., Ahmad, A. (2014): Extracellular biosynthesis of metal sulfide nanoparticles using the fungus Fusarium oxysporum. - Curr Nanosci 10(4): 588-595.

[28] Shahverdi, A. R., Minaeian, S., Shahverdi, H. R., Jamalifar, H., Nohi, A. A. (2007): Rapid synthesis of silver nanoparticles using culture supernatants of Enterobacteria: a novel biological approach. - Process Biochem 42(5) 919-923.

[29] Silva-Ichante, M., Reyes-Vidal, Y., Bácame-Valenzuela, F. J., Ballesteros, J. C., Arciga, E., Ţălu, S., Méndez-Albores, S., Trejo, G. (2018): Electrodeposition of antibacterial Zn$\mathrm{Cu} /$ silver nanoparticle (AgNP) composite coatings from an alkaline solution containing glycine and AgNPs. - J Electroanal Chem 823(June): 328-334.

[30] Tippayawat, P., Phromviyo, N., Boueroy, P., Chompoosor, A. (2016): Green synthesis of silver nanoparticles in aloe vera plant extract prepared by a hydrothermal method and their synergistic antibacterial activity. - J Peer 4: 1-15.

[31] Veerasamy, R., Xin, T. Z., Gunasagaran, S., Xiang, T. F. W., Yang, E. F. C., Jeyakumar, N., Dhanaraj, S. A. (2011): Biosynthesis of silver nanoparticles using mangosteen leaf extract and evaluation of their antimicrobial activities. - J Saudi Chem Soc 15: 113-120.

[32] Vishwasrao, C., Momin, B., Ananthanarayan, L. (2018): Green synthesis of silver nanoparticles using sapota fruit waste and evaluation of their antimicrobial activity. Waste and Biomass Valorization 4(3). DOI: 10.1007/s12649-018-0230-0. 